\title{
Capsular block syndrome: a case report and literature review
}

This article was published in the following Dove Press journal:

Clinical Ophthalmology

13 August 2014

Number of times this article has been viewed

\section{Mauricio Vélez \\ Luis F Velásquez \\ Sebastián Rojas \\ Laura Montoya \\ Katherine Zuluaga \\ Kepa Balparda}

Pontifical Bolivarian University, School of Medicine, Medellín, Antioquia, Colombia

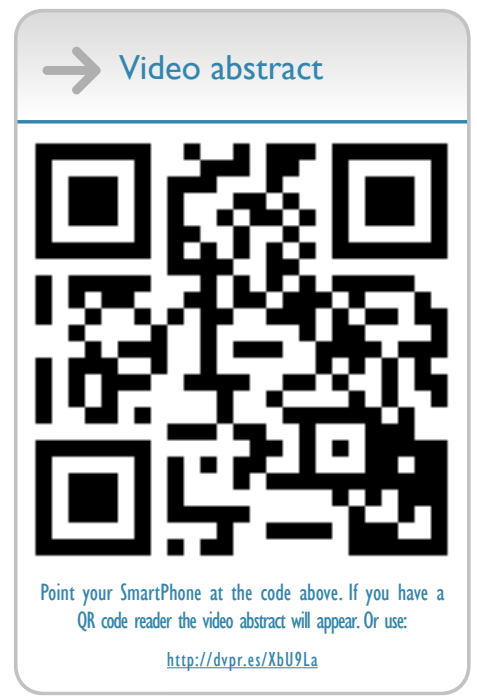

Correspondence: Mauricio Vélez Carrera 48 \#19 A40, office I5I7, Torre Médica, Ciudad del Río, Medellín, Colombia

Email mauroftalmo@hotmail.com
Purpose: To report the case of a patient who developed late capsular block syndrome and to review the current literature regarding this complication of phacoemulsification procedures.

Methods: The literature was reviewed to summarize the diagnosis, classification, use of diagnostic aids, and the current treatments for this complication.

Results: A 69-year-old patient complained of decreased visual acuity 11 months after undergoing phacoemulsification. She was found to have a secondary myopization. Anterior segment ultrabiomicroscopy confirmed the diagnosis of capsular block syndrome. The patient underwent neodymium-doped yttrium aluminum garnet (Nd:YAG) laser posterior capsulotomy, which resulted in complete resolution of her symptoms.

Conclusion: Capsular block syndrome is a fairly rare complication of phacoemulsification procedures that, depending primarily on the timing of its occurrence following surgery, can develop into one of the three following possible clinical scenarios: intraoperatory, early postoperatory, and late postoperatory. In this patient, Nd:YAG laser capsulotomy was shown to be a safe and effective treatment option for this type of complication.

Keywords: continuous curvilinear capsulorhexis, phacoemulsification, cataract

\section{Methods and literature review}

The literature was reviewed to summarize the diagnosis, classification, use of diagnostic aids, and the current treatments for capsular block syndrome. We did not require Institutional Review Board or Ethics Committee approval for any portion of the development, production, or possible publication of this manuscript.

\section{Case description}

The patient was a 69-year-old female who had undergone a phacoemulsification procedure in her right eye 11 months previously. At the time of surgery, a +9.25 D RAYNER $^{\circledR} 620 \mathrm{H}$ intraocular lens (IOL) (Rayner Intraocular Lenses Limited, East Sussex, UK) was implanted with no complications.

The patient presented at our clinic with a complaint of decreased vision in the same eye. Upon ophthalmologic evaluation, she was found to have an uncorrected visual acuity of 20/60 (LogMAR 0.48) in her right eye, which improved to 20/20 (LogMAR 0) with a $-1.00 \mathrm{D}$ spherical correction. Slit-lamp examination ruled out any type of anterior segment inflammation. Her Goldmann intraocular pressure (IOP) was $18 \mathrm{mmHg}$. Her posterior chamber was noted as shallow, with a forward displacement of the iris and a distended capsular bag. The posterior capsule was separated and pushed away from the posterior surface of the lens by a transparent liquid material (Figure 1).

Anterior segment ultrabiomicroscopy (UBM) was used to acquire images from both eyes for comparison. The right eye was found to have a shallow anterior chamber, 


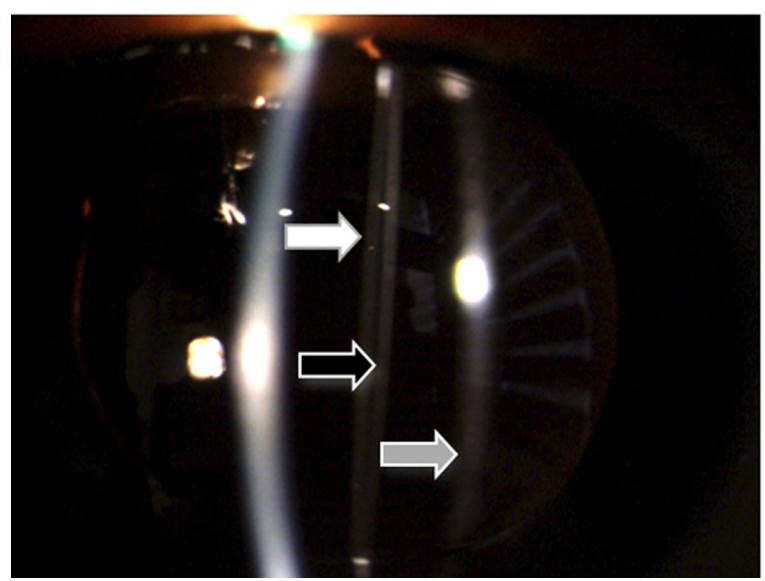

Figure I Anterior segment photography of the right eye.

Notes: White arrow: slit lamp light over the anterior intraocular lens surface. Black arrow: slit lamp light over the posterior intraocular lens surface. Gray arrow: slit lamp light over the posterior capsule.

and the IOL displaced the iris anteriorly. An echonegative space behind the IOL was identified and corresponded to a distended capsular bag (Figure 2A). The IOL of the left eye was in the normal position, and there were no observable changes in the morphology of the capsular bag (Figure 2B). A diagnosis of capsular block syndrome (CBS) was confirmed in the right eye.

The patient underwent neodymium-doped yttrium aluminum garnet (Nd:YAG) laser posterior capsulotomy. This process allowed the liquid inside the capsular bag to be displaced into the vitreous cavity and resolved the IOL displacement (Figures 3, 4, and 5), which in turn resolved the refractive error. On subsequent evaluation, the patient had uncorrected visual acuities of 20/20 (LogMAR 0) in both eyes.

Anterior segment photography using a Scheimpflugbased camera was employed to acquire comparative images of both eyes, but the Scheimpflug imaging failed to capture the displacement of the posterior capsule behind the IOL (Figures 6 and 7).

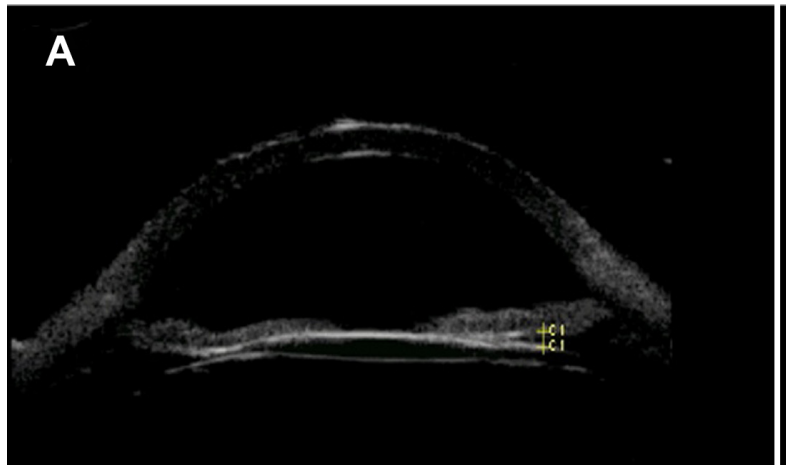

Figure 2 Comparative ultrabiomicroscopies of both eyes. (A) Right eye. The intraocular lens is displacing the iris forward. There is an echo-negative space between the intraocular lens and the distended posterior capsule. (B) Left eye. A normally placed intraocular lens. There is no abnormal contact with any surrounding structure.

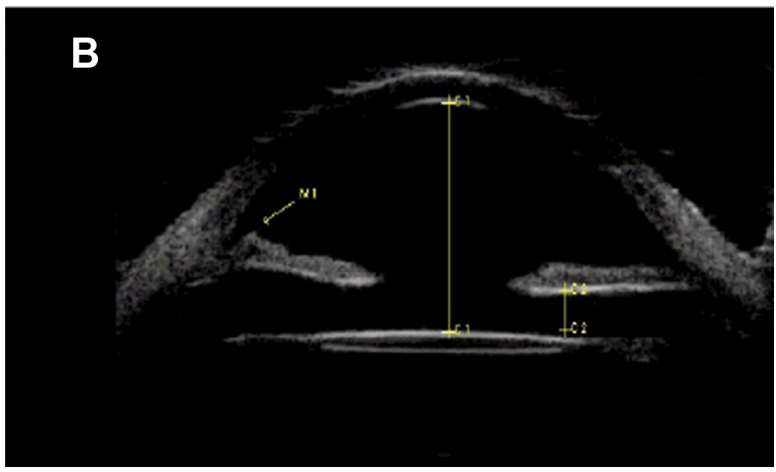

\section{Definition}

CBS is a fairly uncommon complication of phacoemulsification that is characterized by the accumulation of liquid inside the capsular bag, specifically between the posterior capsule and the IOL. A broad spectrum of manifestations of CBS has been reported and includes asymptomatic patients, ocular hypertension, and glaucoma. Visual acuity can be decreased by two mechanisms: myopic shifts induced by the displacement of the effective position of the lens and/or the accumulation of a retrolental white liquid (this phenomenon is termed lacteocrumenasia).

Although the first descriptions of the syndrome were published by Davison ${ }^{1}$ in 1990 and by Holtz ${ }^{2}$ in 1992, it was Masket ${ }^{3}$ who first coined the term CBS to refer to this condition.

\section{Classification}

Based on both chronologic and physiopathological theories, Miyake et $\mathrm{al}^{4}$ proposed the first classification system for CBS in 1998. According to these authors, CBS can present in one of three different scenarios: intraoperative, early postoperative, and late postoperative.

Later, in 2008, a new classification system was proposed by Kim and Shin. ${ }^{5}$ Table 1 presents the classification proposed by Miyake et $\mathrm{al}^{4}$ and Table 2 presents the classification proposed by Kim and Shin. ${ }^{5}$

For the present paper, the authors chose to use the classification system proposed by Miyake et $\mathrm{al}^{4}$ and to apply some of the etiological concepts described by Kim and Shin ${ }^{5}$ and other authors.

\section{Intraoperative capsular block}

Intraoperative capsular block occurs more frequently in white or posterior polar cataracts for which hydrodissection maneuvers involving high irrigation pressures or large volumes are 


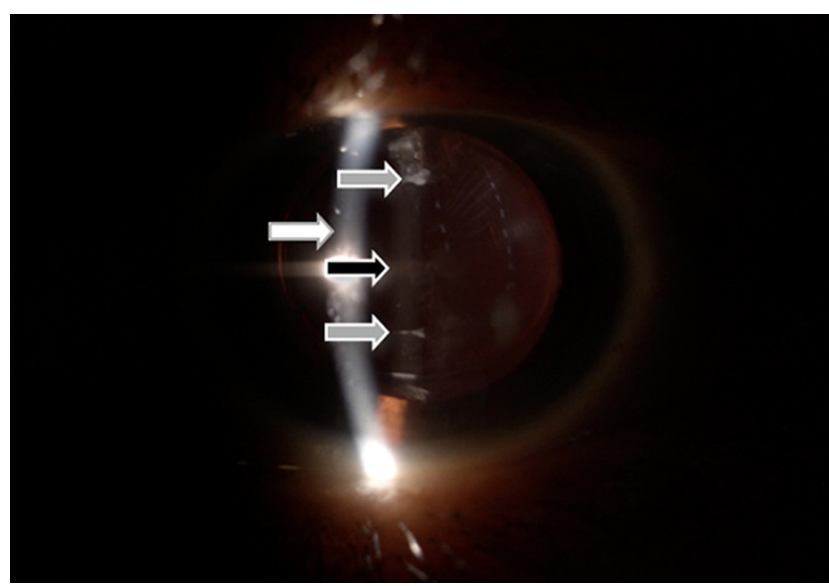

Figure 3 Anterior segment photography of the right eye after Nd:YAG capsulotomy Notes: White arrow, slit-lamp light over the corneal surface; black arrow, slitlamp light over the anterior surface of the intraocular lens; gray arrows, posterior capsulotomy borders.

Abbreviation: Nd:YAG, neodymium-doped yttrium aluminum garnet.

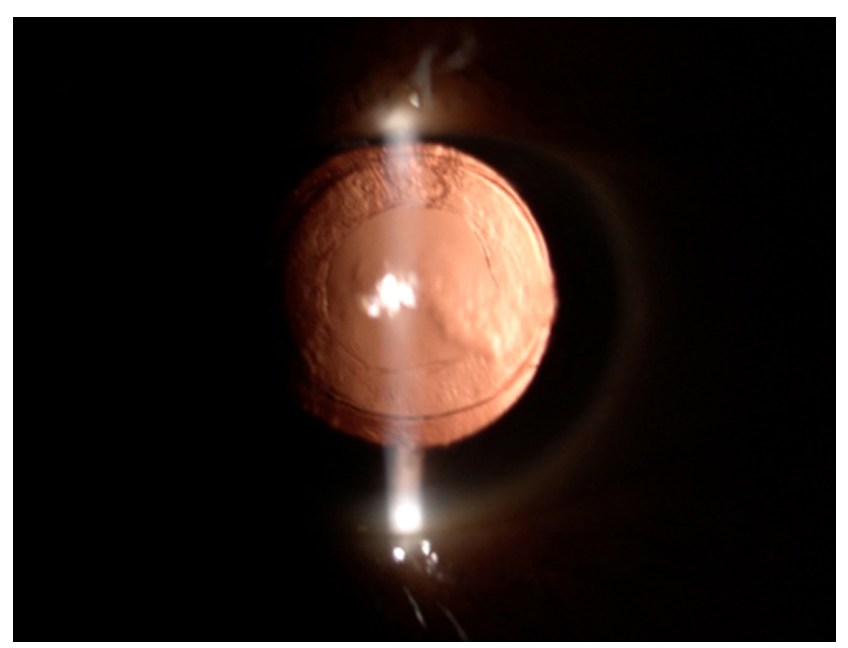

Figure 4 Anterior segment photography of the right eye after Nd:YAG capsulotomy. Abbreviation: Nd:YAG, neodymium-doped yttrium aluminum garnet.

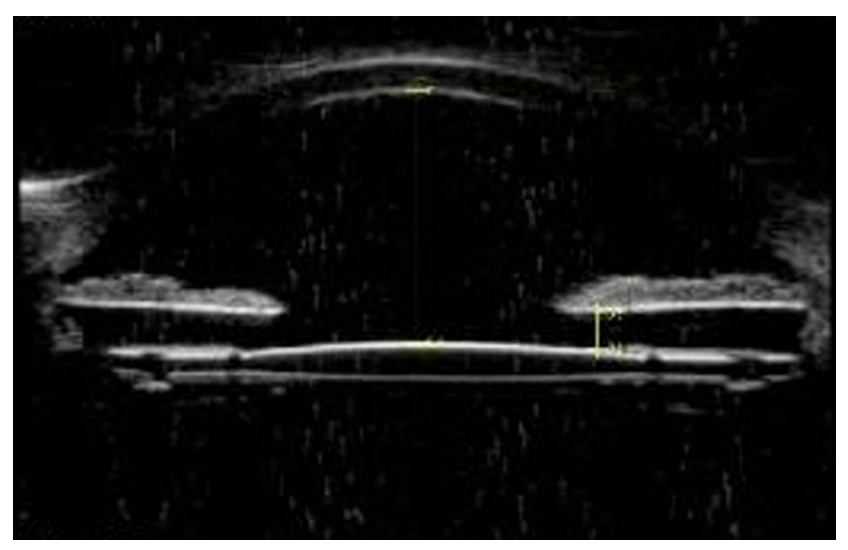

Figure $\mathbf{5}$ Ultrabiomicroscopy of the right eye after Nd:YAG capsulotomy. The capsular block syndrome is resolved. There is no contact between the intraocular lens and the iris.

Abbreviation: Nd:YAG, neodymium-doped yttrium aluminum garnet.

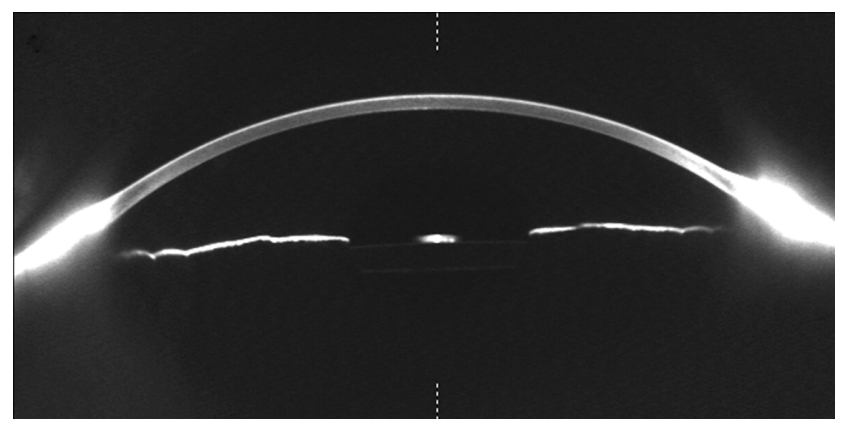

Figure 6 Anterior segment photography of the right eye using a Scheimpflug-based camera.

performed. Under these circumstances, the lens is displaced in a forward direction towards the capsulorhexis borders, which cause an intraoperative CBS. This CBS is characterized by the passage and accumulation of liquid between the posterior capsule of the bag and the posterior lens nucleus. This situation can cause posterior capsular rupture with lens luxation towards the vitreous chamber. ${ }^{4}$

Significant amounts of viscoelastic materials in the anterior chamber constitute a risk factor because the presence of such materials results in increased resistance to the escape of liquid through the capsulorhexis borders, which increases the pressure between the nucleus and the posterior capsule., $4,6-8$

A careful hydrodissection technique is necessary to avoid this complication. The use of a thicker cannula is recommended to slightly decompress the anterior chamber via the evacuation of a portion of the viscoelastic material both before and during the irrigation. The creation of a wide capsulorhexis can also reduce the occurrence of this complication. ${ }^{6}$

\section{Early postoperative CBS}

Early postoperative CBS occurs during the first 2 weeks following surgery. Various mechanisms have been proposed to explain the occurrence of this complication. One of these

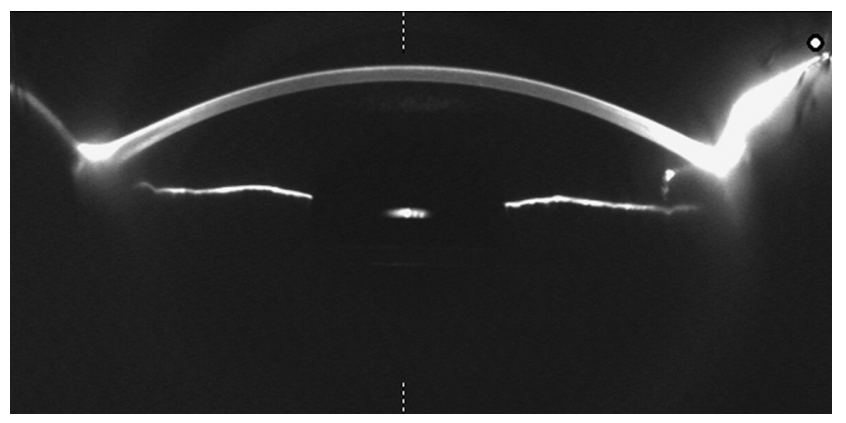

Figure 7 Anterior segment photography of the left eye using a Scheimpflug-based camera. 
Table I Classification according to time of the development of capsular block syndrome

\begin{tabular}{|c|c|c|c|}
\hline $\begin{array}{l}\text { Chronologic classification } \\
\text { of capsular block }\end{array}$ & Intraoperatory & Early postoperatory & Late postoperatory \\
\hline Time to development & Intraoperatory & I-15 days after surgery & $\sim 3.8$ years after surgery \\
\hline Causes & $\begin{array}{l}\text { Rapid hydrodissection, using high } \\
\text { amounts of balanced solution }\end{array}$ & Unknown & $\begin{array}{l}\text { Pseudo-metaplasia of } \\
\text { lens epithelial cells? }\end{array}$ \\
\hline Related anomalies & $\begin{array}{l}\text { Ocular axial length } \\
\text { Posterior polar cataract }\end{array}$ & - & $\begin{array}{l}\text { Breach in blood-aqueous } \\
\text { barrier? }\end{array}$ \\
\hline Blocking substance & Cataract nucleus & IOL optic & IOL optic \\
\hline Accumulated substance & Balanced solution & Transparent viscoelastic & Whitish liquid \\
\hline Shallow anterior chamber & Yes & Yes or no & Yes \\
\hline IOP increase & No & Yes or no & Yes \\
\hline Refractive change & - & Myopic shift & No \\
\hline Complications & Posterior capsule rupture & Closed angle glaucoma & $\begin{array}{l}\text { Visual acuity decline } \\
\text { (fairly rare) }\end{array}$ \\
\hline Treatment & Posterior vitrectomy & Nd:YAG laser & Nd:YAG laser \\
\hline Prophylaxis & Careful hydrodissection & $\begin{array}{l}\text { Removal of intraoperative } \\
\text { viscoelastic }\end{array}$ & Removal of residual cells \\
\hline
\end{tabular}

Abbreviations: IOL, intraocular lens; IOP, intraocular pressure; Nd:YAG, neodymium-doped yttrium aluminum garnet.

mechanisms is the accumulation of viscoelastic material behind the IOL, as described by Miyake et al in their original report. ${ }^{4}$ This accumulation was proven by Sugiura et al ${ }^{9}$ who showed that this liquid is diluted sodium hyaluronate. This form of CBS was described by Kim and $\mathrm{Shin}^{5}$ as non-cellular postoperative CBS.

Another plausible mechanism of CBS is that the retrolental viscoelastic materials or trapped lens fragments may induce an osmotic gradient that may fill the retrolental space with liquid. ${ }^{4,5,9,10} \mathrm{CBS}$ due to this mechanism has been termed inflammatory postoperative CBS and is thought to occur due to an exudative process in the epithelial cells of the lens. ${ }^{5}$

Based on a number of experimental models, Zacharias ${ }^{11}$ proved that capsulorhexes with adherences that comprise more than $70 \%$ of the border tend to act as valve mechanisms that allow the unidirectional passage of liquid into the retrolental space. Tognetto et $\mathrm{l}^{12}$ provided evidence supporting Zacharias' findings and when they published a case report of a 78-year-old patient with a history of congenital nistagmus who underwent phacoemulsification with a circular continuous capsulorhexis and eventually developed CBS and secondary myopia. ${ }^{12}$

All of these mechanisms displace the IOL and iris in the anterior direction and therefore decreases the anterior chamber depth and alter the anatomical disposition of the iridocorneal angle. If this process is continuous, secondary ocular hypertension and glaucoma may ensue. ${ }^{10}$ The forward displacement of the IOL causes a change in the focal point position and therefore induces secondary myopia. ${ }^{5,10}$ Due to their higher displacement capabilities, flexible IOLs have been associated with an increased risk of developing CBS. ${ }^{1,2}$

Although some of these cases resolve spontaneously, most cases eventually require either anterior or posterior Nd:YAG laser capsulotomy to resolve the capsular block. ${ }^{3}$

\section{Late postoperative capsular block}

Late postoperative CBS is also known as lacteocrumenasia. On average, late postoperative CBS occurs 3.8 years after surgery and can be identified by the deposition of white

Table 2 Pathophysiological classification of CBS as proposed by Kim and Shin

\begin{tabular}{llll}
\hline Parameter & Fibrotic & Inflammatory & Non-cellular \\
\hline Expected main cause & Lens epithelial cell proliferation and & $\begin{array}{l}\text { Inflammatory anterior chamber } \\
\text { cellular reaction }\end{array}$ & Remaining OVD \\
Pseudometaplasia & Late postoperative period (several & Early postoperative period \\
Time of onset & months to years after surgery) & (several days after surgery) & $\begin{array}{l}\text { Very early postoperative period (from } \\
\text { one to several days after surgery) }\end{array}$ \\
Treatment & Disruption of capsular bag & Anti-inflammatory drugs & $\begin{array}{l}\text { Disruption of capsular bag or aspiration } \\
\text { of retained OVDs }\end{array}$ \\
\hline
\end{tabular}

Note: Reprinted from Journal of Cataract and Refractive Surgery, 34(3), Kim HK, Shin JP, Capsular block syndrome after cataract surgery: clinical analysis and classification, 357-363, copyright @2008, with permission from Elsevier.

Abbreviations: CBS, capsular block syndrome; OVD, ophthalmic viscosurgical device. 
material behind the IOL inside the capsular bag. ${ }^{13}$ Eifrig $^{14}$ showed that this white liquid contains high concentrations of alpha-crystallin and relatively low albumin levels, which suggests that the liquid may originate from the epithelial cells of the cataract. Kim and $\mathrm{Shin}^{5}$ proposed that fibrotic changes around the borders of the capsulorhexis might "glue" the capsule to the IOL. The proliferation and pseudo-metaplasia of the lens epithelium may provide the origin of the whitish material that fills the retrolental space. According to the classification proposed by Kim and Shin, ${ }^{5}$ this condition is known as fibrotic postoperative CBS.

Blood-aqueous barrier malfunctions have been found in over half of these patients, and such malfunctions are particularly common in cases of diabetes mellitus and other comorbidities. ${ }^{13,14}$

This type of capsular block may compromise visual acuity to a certain extent, although this is not common. Decreases in the depth of the anterior chamber and increases in the IOP are not characteristic of this type of CBS. ${ }^{14}$

Although Kim and Shin's ${ }^{5}$ theories seem reasonable, they suffer from two specific drawbacks. First, direct experimental confirmation for any of these theories is lacking. Second, the numbers of cases in each classification group are rather small, which makes the study of such cases difficult. Nevertheless, the authors do believe that this classification system is of significant clinical importance, particularly for the evaluation of individual cases and the contemplation of different diagnostic and treatment alternatives. ${ }^{5}$

\section{Diagnosis}

In postoperative contexts, a number of elements might help to reach a diagnosis of CBS. Most frequently, physical examination alone is sufficient for a diagnosis. CBS can be diagnosed in patients with postoperative myopia or refractive surprises when a shallow anterior chamber and a distended capsular bag with IOL separation are found. If the clinician finds inflammatory elements, such as cellularity or flare, then inflammatory CBS is diagnosed, and appropriate treatment is initiated. The absence of inflammatory signs is suggestive of a non-cellular type of postoperative CBS that is associated with the retention of viscoelastic material. The presence of a whitish liquid in the retrolental space is compatible with the late postoperative type of capsular block.

A definitive diagnosis and better characterization of anatomical structures can be achieved via the use of diagnostic aids such as anterior segment UBM, optical coherence tomography and Scheimpflug-based photography.

\section{Optical coherence tomography (OCT)}

OCT of the anterior segment is a well-known, noninvasive, diagnostic technique with resolutions that range from 2 to 20 microns and the capability of performing a fine evaluation of most of the anterior segment structures. Nevertheless, this technique is not well suited for detecting or measuring the structures located behind the iris due to the light-blocking properties of the double-pigmented epithelium of the iris. IOL optics, haptics, and the surrounding structures cannot be fully evaluated with OCT. ${ }^{15-17}$

\section{Scheimpflug-based photography (Pentacam)}

Anterior segment photography with a Scheimpflug-based camera is regarded as one of the best imaging techniques for examining the position of the IOL. ${ }^{18}$ This technique is also known to provide reliable information about the presence and progression of posterior capsule opacifications, including CBS. ${ }^{19}$

The main disadvantage of Scheimpflug-based photography is the inability to view or characterize the iridocorneal angle. ${ }^{20}$

\section{UBM}

The main advantage of UBM over other imaging techniques is that this technique allows for the effective evaluation of the iridocorneal angle and all of the structures surrounding the IOL's optic and haptics. ${ }^{21}$ Thus, UBM enables the evaluation of all of the anatomic aspects of the patient and the determination of the disease. The main disadvantage is likely the fact that the performance of UBM requires direct contact with the eye; therefore, this technique requires a higher level of patient collaboration. Moreover, as an operator-dependent technique, the person performing the test must obviously be experienced to arrive at the correct diagnosis. ${ }^{16}$

\section{Treatment}

To provide the best treatment option, the clinician must account for all of the variables in every case to individualize the approach. Next, we review the current treatment strategies for CBS.

\section{Observation}

Spontaneous resolution of the capsular block is observed in a number of cases; therefore, observation may be a viable option for some patients, particularly during the first month after surgery. ${ }^{22}$ In a total of 13 evaluated cases, Durak et al ${ }^{24}$ reported spontaneous resolution in $15 \%$ of subjects. 


\section{Topical steroids}

Topical steroids can be all that is required to reverse capsular block in cases of postsurgical CBS in which inflammatory processes are the predominant causative factor. ${ }^{5}$

\section{Anterior or posterior capsulotomy with a Nd:YAG laser}

Nd:YAG laser capsulotomy is the treatment of choice for both early postoperative and non-cellular late postoperative CBS. This technique allows for the rapid evacuation of liquid toward either the anterior or the vitreous chamber, which results in the quick resolution of CBS and IOL repositioning. ${ }^{23}$ Durak et $\mathrm{al}^{24}$ recommend performing anterior capsulotomy first, as this technique may be technically easier and safer than the posterior technique. ${ }^{24}$ Nevertheless, Colakoglu et $\mathrm{al}^{25}$ raised the issue of whether this approach is the best approach. These authors found a significantly lower success rate and higher recurrence rate among patients who underwent anterior capsulotomy compared with those who underwent posterior capsulotomy.

\section{Nd:YAG laser peripheral iridotomy and anterior capsulotomy}

Peripheral iridotomy plus anterior capsulotomy is a viable technique for cases of late postoperative CBS with poor mydriasis in which the whitish liquid does not allow for the proper visualization of the posterior capsule. ${ }^{26}$ Grover et al described this procedure, which begins with an argon and Nd:YAG laser iridotomy and proceeds with a Nd:YAG anterior capsulotomy. ${ }^{26}$

After this procedure, timolol ( $0.5 \%$ twice daily) and prednisolone ( $1 \%$ four times daily) are administered to reduce the possibility of increased IOP peaks due to liberated liquid.

\section{Needle revision}

Slit-lamp needle revision can be a viable technique for some cases of CBS. Tropicamide, proparacaine, and iodopovidone are instilled into the eye, and an ocular speculum is placed in position. A 30-gauge needle is inserted, bevel-down, through the peripheral cornea away from the position of the original phaco incision. The tip of the needle is used to gently press the IOL backwards in an attempt to move the trapped liquid towards the anterior chamber. This movement is repeated as many times as is needed for the liquid to be removed from the retrolental space. The cornea must be examined to ensure that the results of the Seidel are negative. Topical antibiotics are prescribed to reduce the risk of secondary infection. IOP should be measured 1 hour after the needle revision.
This treatment is relatively easy to perform and does not involve the costs of an additional surgery for the patient. Additionally, this treatment does not require the use of a laser and can be performed as soon as 1 day after the original phaco surgery. Mardelli ${ }^{27}$ has used this technique in eight eyes of patients with early postoperative CBS and reported excellent results without complications or recurrences.

The main disadvantages of this procedure are uncontrollable filtration (which can be avoided with an adequate $1.5 \mathrm{~mm}$ corneal tunnel), IOP changes, anterior chamber inflammation, endophthalmitis, ${ }^{28}$ and the possibility of scratching the lens. Obviously, excellent patient collaboration is imperative to the safety of this procedure.

\section{Surgical management}

Proper asepsis techniques are employed, and a blepharostat is placed in position. A scleral tunnel is built, and viscoelastic material ( $1 \%$ sodium hyaluronate) is injected into the anterior chamber. A 27 -gauge needle on a $1 \mathrm{~mL}$ syringe is inserted through the scleral tunnel to penetrate the anterior capsule at 12 o'clock position. The needle is used to press down between the IOL optic and the posterior capsule to aspirate the liquid. Next, Vannas' scissors are used to remove all fibrotic tissue on the anterior capsule. Aspiration of the viscoelastic material is performed, and the anterior chamber is formed using balanced solution. Qu et $\mathrm{al}^{22}$ have used this technique in a total of four eyes with late CBS with excellent results.

This procedure has been shown to be effective in cases of late CBS in which the dark white liquid makes it nearly impossible to aim the Nd:YAG laser. Additionally, performing a capsulotomy in the presence of such thick liquid may expose the patient to a greater risk of IOP because the trabecular meshwork can be at least partially obstructed by the collagen-rich matrix that forms the lacteocrumenasia. ${ }^{22}$

\section{Disclosure}

The authors report no conflicts of interest in this work.

\section{References}

1. Davison JA. Capsular bag distension after endophacoemulsification and posterior chamber intraocular lens implantation. J Cataract Refract Surg. 1990;16:99-108.

2. Holtz SJ. Postoperative capsular bag distension. J Cataract Refract Surg. 1992;18:310-317.

3. Masket S. Postoperative complications of capsulorhexis. J Cataract Refract Surg. 1993;19:721-724.

4. Miyake K, Ota I, Ichihashi S, et al. New classification of capsular block syndrome. J Cataract Refract Surg. 1998;24:1230-1234.

5. Kim HK, Shin JP. Capsular block syndrome after cataract surgery: clinical analysis and classification. J Cataract Refract Surg. 2008;34: 357-363. 
6. Osher RH, Yu BCY, Koch DO. Posterior polar cataracts: a predisposition to intraoperative posterior capsular rupture. J Cataract Refract Surg. 1990;16:157-162.

7. Ora I, Miyake S, Miyake K. Dislocation of the lens nucleus into the vitreous cavity after standard hydrodissection. Am J Ophthalmol. 1996; 121:706-708.

8. Hashimoto T, Izutani M, Tanaka Y, et al. Two cases of posterior capsular rupture and dislocation of lens nucleus following hydrodissection. Folia Ophthalmol Jpn. 1994;45:973-976.

9. Sugiura T, Miyauchi S, Eguchi S, et al. Analysis of liquid accumulated in the distended capsular bag in early postoperative capsular block syndrome. J Cataract Refract Surg. 2000;26:420-425.

10. Theng JTS, Jap A, Chee S-P. Capsular block syndrome: a case series. $J$ Cataract Refract Surg. 2000;26:462-467.

11. Zacharias J. Early postoperative capsular block syndrome related to saccadic-eye-movement-induced fluid flow into the capsular bag. $J$ Cataract Refract Surg. 2000;26:415-419.

12. Tognetto D, Toto L, Michieli C, et al. Capsular block syndrome associated with horizontal jerk nystagmus. J Cataract Refract Surg. 2002;28: 1487-1489.

13. Miyake K, Ota I, Miyake S, Horiguchi M. Liquefied after cataract: a complication of continuous curvilinear capsulorhexis and intraocular lens implantation in the lens capsule. Am J Ophthalmol. 1998; 125:429-435.

14. Eifrig DE. Capsulorhexis-related lacteocrumenasia. J Cataract Refract Surg. 1997;23:450-454.

15. Ramos JL, Li Y, Huang D. Clinical and research applications of anterior segment optical coherence tomography - a review. Clin Experiment Ophthalmol. 2009;7:81-89.

16. Wolffsohn JS, Davies LN. Advances in anterior segment imaging. Curr Opin Ophthalmol. 2007;18:32-38.

17. Kucukevcilioglu M, Hurmeric V, Erdurman FC, Ceylan OM. Imaging late capsular block syndrome: ultrasound biomicroscopy versus Scheimpflug camera. J Cataract Refract Surg. 2011;37:2071-2074.
18. Montés-Micó R, Cerviño A, Ferrer-Blasco T. Intraocular lens centration and stability: efficacy of current technique and technology. Curr Opin Ophthalmol. 2009;20:33-36.

19. Jain R, Grewal D, Gupta R. Scheimpflug imaging in late capsular. Am J Ophthalmol. 2007;142:1083-1085.

20. Wegener A, Laser-Junga H. Photography of the anterior eye segment according to Scheimpflug's principle: options and limitations - a review. Clin Experiment Ophthalmol. 2009;37:144-154.

21. Nolan W. Anterior segment imaging: ultrasound biomicroscopy and anterior segment optical coherence tomography. Curr Opin Ophthalmol. 2008;19:115-121.

22. Qu J, Bao Y, Li M, et al. Surgical management of late capsular block syndrome. J Cataract Refract Surg. 2010;36:1687-1691.

23. Pinsard L, Rougier MB, Colin J. Neodymium YAG laser treatment of late capsular block syndrome. J Cataract Refract Surg. 2011;37: 2079-2080.

24. Durak I, Ozbek Z, Ferliel ST, Oner FH, Söylev M. Early postoperative capsular block syndrome. J Cataract Refract Surg. 2001;27:555-559.

25. Colakoglu A, Kucukakyuz N, Topcuoglu IE, et al. Intraocular pressure rise and recurrence of capsular block syndrome after neodymium:YAG laser anterior capsulotomy. J Cataract Refract Surg. 2007;33: 1344-1346.

26. Grover DS, Goldberg RA, Ayres B, et al. Treatment of late-onset capsular distension syndrome with a neodymium:YAG laser peripheral iridotomy and anterior capsulotomy. J Cataract Refract Surg. 2012;38: 938-940.

27. Mardelli PG. Slitlamp needle revision of capsular block syndrome. J Cataract Refract Surg. 2008;34:1065-1069.

28. Joondeph BC, Joondeph HC. Purulent anterior segment endophthalmitis following paracentesis. Ophthalmic Surg. 1986;17:91-93.
Clinical Ophthalmology

\section{Publish your work in this journal}

Clinical Ophthalmology is an international, peer-reviewed journal covering all subspecialties within ophthalmology. Key topics include: Optometry; Visual science; Pharmacology and drug therapy in eye diseases; Basic Sciences; Primary and Secondary eye care; Patient Safety and Quality of Care Improvements. This journal is indexed on

\section{Dovepress}

PubMed Central and CAS, and is the official journal of The Society of Clinical Ophthalmology (SCO). The manuscript management system is completely online and includes a very quick and fair peer-review system, which is all easy to use. Visit http://www.dovepress.com/ testimonials.php to read real quotes from published authors. 